\title{
Further Thoughts on Strategic Trade Policy under Asymmetric Information
}

\author{
Chung Yuan Fu', Shirley J. Ho \\ Department of Economics National Chengchi University, Taiwan \\ Email: ${ }^{*}$ fu.chungyuan@gmail.com, sjho@nccu.edu.tw
}

Received July 3, 2013; revised August 1, 2013; accepted August 9, 2013

Copyright (C) 2013 Chung Yuan Fu, Shirley J. Ho. This is an open access article distributed under the Creative Commons Attribution License, which permits unrestricted use, distribution, and reproduction in any medium, provided the original work is properly cited.

\begin{abstract}
We study the informational impacts of multilateral voluntary export restraints (henceforth VERs) in an international trade model with differentiated products [1]. We first show that with competing mechanisms, the two firms' lying intentions are strategic complements and will increase with the degree of product differentiation. Next, we show that each government will design their VERs menus to allow for only partial revelation. Contrary to the single intervention case [2], a separating equilibrium where each country's domestic firm truthfully reveals its private information does not exist under multilateral policy interventions. Finally, we demonstrate that trade retaliation, when the two governments' VERs are positively related, will happen when the government believes that its domestic firm is more likely to be inefficient.
\end{abstract}

Keywords: Strategic Trade Policy; Voluntary Export Restraints; Partial Information Revelation

\section{Introduction}

It is now well known that government intervention can shift rents by providing a strategic advantage to the domestic firm. In particular, the pioneering work by Brander and Spencer [3] showed that under Cournot competition, an export subsidy enables the domestic firm to be a Stackelberg leader, and thus it increases the domestic welfare at the expense of the foreign firm. Subsequently, Eaton and Grossman [4] demonstrated that the optimal policy will be an export tax, when the domestic firm competes with a foreign firm in prices ${ }^{1}$. This indicates that the type of export policy is sensitive to the form of competition. In addition, the literature has also noticed that information can also crucial in determining the appropriate policy. For example, Wong [5] demonstrated that in the Brander-Spencer model with asymmetric information (about cost), the optimal export subsidy scheme derived from the full information case is no longer incentive compatible. Collie and Hviid [6] and

\footnotetext{
Corresponding author.

${ }^{1}$ De Meza [7] considered cost asymmetry between firms and shows that the countries with the lowest costs provide the highest export subsidies. Allowing a social cost of public funds that exceeds unity, Neary [8] similarly found that non-concavity of demand is a sufficient condition for the government to provide more subsidies to the more cost competitive firm. Bandyopadhyay [9] found the conventional result in De Meza [7] and Neary [8] is reversed for inelastic demand.
}

Qiu [2] examined the use of strategic trade policy as a signalling device when the informational asymmetry is between domestic and foreign firms.

With incomplete information, the Principal-Agent model can best describe the leader-follower relation between uninformed government and informed firm. By applying the Revelation Principle, the uninformed government can adopt a direct mechanism by offering a menu of policies and letting the informed domestic firm self-select the intended policy. When domestic firm is competing with foreign firms, this "self-selection" process becomes more informative. In Qiu's [2] words, "it is a mix of screening and signalling problems"; by choosing among the menu of policies, the domestic firm also signals its private information to the rival firms [6]. The task of the government is then to trade off between the inefficiency from asymmetric information and the strategic advantage from trade policy; whether to have the informed domestic firm truly reveal its information, or to hide and enjoy the strategic benefit from asymmetric information? Qiu [2] showed that under Cournot competition the uniformed government will choose a policy menu to truly reveal its cost information (separating equilibrium).

While the analysis on unilateral policy intervention has proved to be powerful to describe the dilemma encountered by the uninformed government, in reality we often 
see bilateral or multilateral policy interventions instead of unilateral policy. If we adopt a direct mechanism for these multiple contracting cases, will there be a separating equilibrium? If not, how much information can be revealed? How does the degree of information revelation relate to the market structure? Will there be trade retaliation?

In this paper, we provide answers to these questions by studying an incomplete information VERs game in an intra-industry trade model. The model we consider is an international trade model with differentiated products [1]. There are two countries and each country has only one producer, which sells its products to two countries. In order to capture intra-industry trade of this kind, we employ the differentiated product framework by Dixit [10] and Singh and Vives [11]. There are three reasons to study an incomplete information VERs game of this form. First, there have been many discussions on the informational impacts of taxes, subsidies or tariffs; we hope to complement the literature by investigating the informational impacts of VERs, which are seen as equally important strategic tools. Second, although we are aware that both the choice of policy instrument and the degree of information revelation can be sensitive to the form of competition (Cournot or Bertrand), since our focus is on the information aspects of multilateral interventions, we adopt a quantity competition setup to better handle the impacts from VERs.

Third and most interestingly, we will show that in the complete information benchmark case, each government's VER decision is as efficient as in the single government case. There is no direct interaction between the two governments, so the policy efficiency can be retained even with bilateral interventions. The question of concern is: now that there is no game between the two governments, can we apply the revelation principle directly and look for a truth-telling direct mechanism in the incomplete information VERs game? Unfortunately, the answer is no, as we will demonstrate that the "signaling effect" of menu selection will change the rival firm's perception about domestic firm's private information. Consequently, each firm's intention of information revelation will be related to the rival firm's intention, and thus the two governments are no longer "independent" from each other.

Our paper starts with the complete information benchmark case, where we show that, by using VER each government gains a first mover advantage in the rival country [12-14]. However, when considering incomplete information, we first demonstrate that with competing mechanisms, each firm's intention to lie is positively related to the rival firm's lying intention. The two firms' lying intentions are strategic complements and will increase with the degree of product differentiation. Impor- tantly, we show that each government will design their VERs menus to allow for only partial revelation. Contrary to the single intervention case [2], a separating equilibrium where each country's domestic firm truthfully reveals its private information does not exist with multilateral policy interventions. Finally, we demonstrate that trade retaliation, when the two governments' VERs are positively related, will happen when the government believes that its domestic firm is more likely to be inefficient. This result partly reflects the result by Martina and Vergoted [15], who discussed the role of retaliation in trade agreements and showed that retaliation is a necessary feature of any efficient equilibrium.

The issues on "competing mechanisms" have received many discussions. Peck [16] and Martimort and Stole [17] first illustrated apparent failures of the standard revelation principle with competing mechanisms. Since there is no obvious way to deal with these problems, the literature has responded by imposing ad hoc restrictions on the set of mechanisms from which Principals can choose [18-22]. This is the reason why we stick to direct mechanisms in this current paper. Next, our paper investigates ex-post information revelation under bilateral government interventions. This is different from ex-ante information revelation such as Creane and Miyagiwa [23], where duopoly firms make their revelation decisions before they observe their own private information. From the information content, our model is closed to Collie and Hviid [6] and Qiu [2], but they mainly assumed unilateral policy design. Brainard and Martimort [21] considered bilateral government interventions but restricted to truth-telling equilibria ${ }^{2}$. Finally, our results conclude that trade retaliation happens when the government believes that its domestic firm is more likely to be inefficient. This partly coincides with Martina and Vergoted's [15] results. They showed that in the presence of private information, retaliation can always be used to increase the welfare derived from such agreements by the participating governments. In particular, it is shown that retaliation is a necessary feature of any efficient equilibrium.

The remainder of the paper is organized as follows. Section 2 discusses the complete information VERs game as a benchmark of comparison. We demonstrate that, by using VER, each government gains a first mover advantage in the rival country. Section 3 characterizes the equilibrium in the incomplete information VERs game. In equilibrium, each government will only implement partial revelation from its domestic firm, and there can be trade retaliation when the government believes that its

\footnotetext{
${ }^{2}$ Brainard and Martimort [21] restricted to truth revelation equilibrium, because Myerson [24] showed that in a bilateral principal-agent structure, truth revelation will be an equilibrium, if each agent is associated uniquely with one principal. In our model, each firm will be related to both governments, and hence truthful revelation does not constitute an equilibrium.
} 
domestic firm is more likely to be inefficient. Section 4 concludes the paper with some suggestions on further research.

\section{The Model}

Specifically, let the superscript $k=1,2$, index the two countries. Country $k$ 's demand for firm 1 and firm 2's products are given by

$$
\begin{aligned}
& p_{1}^{k}=\alpha-\beta q_{1}^{k}-\gamma q_{2}^{k}, \\
& p_{2}^{k}=\alpha-\gamma q_{1}^{k}-\beta q_{2}^{k},
\end{aligned}
$$

where subscript $i, i=1,2$, indexes firm $i . p_{i}^{k}$ and $q_{i}^{k}$ denote firm $i$ 's price and output in country $k$. The coefficients $\beta$ and $\gamma$ denote the own price effect and cross price effects, respectively. We assume $\beta>\gamma$ to reflect that the own price effect is higher than the cross effects. Notice that the level of $\gamma$ can be seen as a measure for the substitution between the two products; When $\gamma \rightarrow \beta$ the two products are almost homogenous; when $\gamma \rightarrow 0$ the two products are almost differentiated.

The reason we have considered a quantity instead of price competition model is because we can handle the quantity restraints easily. We are aware that the form of competitionmight changes the policy insights [4]. Since our focus is on the informational impacts of VERs, we will stick to this simple framework for a neat presentation. Finally, since our focus is on the informational impacts of government interventions, we assume zero transportation cost for simplification. Each firm's marginal production is assumed to be $c_{i}$.

Each firm's profit $\pi_{i}$ is thus given by

$$
\pi_{i}=R_{i}^{i}+R_{i}^{j}-c_{i}\left(q_{i}^{i}+q_{i}^{j}\right), \quad i=1,2,
$$

where $R_{i}^{i} \equiv p_{i}^{i} q_{i}^{i}$ and $R_{i}^{j}=p_{i}^{j} q_{i}^{j}$ denote firm $i$ 's revenue in domestic $(i)$ and foreign $(j)$ countries, respectively.

We consider that the government of each country will choose a VER $q_{i}^{j}, i \neq j$, to maximize social welfare $S W_{i}$. Each country's social welfare is the overall utility deducted by foreign firm's revenue, added by domestic firm's revenue in the foreign country, and minus the domestic firm's total production cost. That is,

$$
S W_{i}=U_{i}-R_{j}^{i}+R_{i}^{j}-c_{i}\left(q_{i}^{i}+q_{i}^{j}\right) \text {, for } i=1,2 \text {, and } i \neq j \text {. }
$$

This setup is firstly given by Singh and Vives [11], which assumed that

$$
U_{i} \equiv \alpha\left(q_{i}^{i}+q_{i}^{j}\right)-\left[\beta\left(q_{i}^{i}\right)^{2}+2 \gamma q_{i}^{i} q_{j}^{i}+\beta\left(q_{j}^{i}\right)^{2}\right] / 2, i \neq j .
$$

The advantage of this setup is: since in differentiated product models, we cannot use the area under demand function to measure the consumer surplus. The setup of $U_{i}$ can help us easily measure the consumer surplus.
Also, we can easily derive the country $i$ 's demand function by partial differentiating $U_{i}$ with respect to $q_{i}^{i}$.

\section{Complete Information VERs Game}

As a benchmark of comparison, Section 2 discusses the complete information VERs game where both firms' production costs are publicly known. We will show that, under complete information, each government's VER decision will be as efficient as in the single government case. However, this policy efficiency will disappear when we consider incomplete information in Section 3. Not only because there is information rent in the VERs contract, but also because the two governments' competing mechanisms will increase firms' strategic incentives to lie.

The complete information VERs game proceeds as follows. First, government 1 and government 2 set their VERs, $q_{1}^{2}$, and $q_{2}^{1}$ simultaneously. After observing the VER decisions, both firm 1 and firm 2 compete in the product markets of the two countries. By backward induction, we first solve the market equilibrium, given the two governments' VER decisions, and then determine each government's optimal VER.

Market Equilibrium Given the two governments' VER decisions, $q_{1}^{2}$ and $q_{2}^{1}$ firm 1 and firm 2 maximize their profits simultaneously.

$$
\begin{aligned}
& \max _{q_{1}^{1}} \pi_{1}=R_{1}^{1}+R_{1}^{2}-c_{1}\left(q_{1}^{1}+q_{1}^{2}\right), \\
& \max _{q_{2}^{2}} \pi_{2}=R_{2}^{1}+R_{2}^{2}-c_{2}\left(q_{2}^{1}+q_{2}^{2}\right) .
\end{aligned}
$$

Each firm's best reply to the rival government's VER is given by

$$
q_{1}^{1}=\frac{\alpha-\gamma q_{2}^{1}-c_{1}}{2 \beta} \text { and } q_{2}^{2}=\frac{\alpha-\gamma q_{1}^{2}-c_{2}}{2 \beta} .
$$

Optimal VERs Now, given the two firms' best replies in (1), each government chooses its VER to maximize its social welfare. In the case of country 1 , the structural form of $S W_{1}$ is:

$$
\begin{aligned}
S W_{1} & =\alpha\left(q_{1}^{1}+q_{2}^{1}\right)-\left[\beta\left(q_{1}^{1}\right)^{2}+2 \gamma q_{1}^{1} q_{2}^{1}+\beta\left(q_{2}^{1}\right)^{2}\right] / 2 \\
& -\left\{\left(\alpha-\beta q_{1}^{1}-\gamma q_{2}^{1}\right) q_{2}^{1}\right\} \\
& +\left\{\left[\alpha-\beta\left(\frac{\alpha-\gamma q_{1}^{2}-c_{2}}{2 \beta}\right)-\gamma q_{1}^{2}\right] q_{1}^{2}\right\}-c_{1}\left(q_{1}^{1}+q_{1}^{2}\right) .
\end{aligned}
$$

From the first order condition of maximization: $\frac{\partial S W_{1}}{\partial q_{1}^{2}}=\frac{\alpha+c_{2}}{2}-\gamma q_{1}^{2}-c_{1}=0^{3}$. Therefore

\footnotetext{
${ }^{3}$ The second order condition of maximization is satisfied.
} 


$$
\bar{q}_{1}^{2}=\frac{1}{2 \gamma}\left(\alpha-2 c_{1}+c_{2}\right)
$$

Similarly, we can calculate government 2's optimal VER: $\bar{q}_{2}^{1}=\frac{1}{2 \gamma}\left(\alpha-2 c_{2}+c_{1}\right)$. We will later refer $\bar{q}_{1}^{2}$ and $\bar{q}_{2}^{1}$ as the efficient VERs, as each government's VER decision is as efficient as in the single government case.

Accordingly, substitute $\bar{q}_{i}^{j}, i \neq j$, into firms' best replies in (1), we have $q_{1}^{1}=\frac{\alpha-3 c_{1}+2 c_{2}}{4 \beta}$ and $q_{2}^{2}=\frac{\alpha-3 c_{2}+2 c_{1}}{4 \beta}$.

Here we make two remarks on these efficient VERs. First, we can compare $\bar{q}_{i}^{j}$ to the outputs in the free trade case, where each firm choose both $q_{i}^{i}$ and $q_{i}^{j}, i \neq j$, to maximize $\pi_{i}$. The free trade outputs in domestic and foreign markets are $\tilde{q}_{i}^{i}=\frac{\alpha-2 c_{i}+c_{j}}{3 \beta}$ and $\tilde{q}_{i}^{i}=\frac{\alpha-2 c_{i}+c_{j}}{3 \beta}$, respectively. A direct comparison shows that The VER is higher than the foreign output in the free trade case. The advantage of using VER is that, by pre-committing to $\bar{q}_{i}^{j}$, the government gains the position of a leader in the rival country, and in output competition, there will be a first mover advantage.

This strategic advantage is first mentioned by Harris [12], who analyzed the impacts of VERs in a Bertrand model. Rosendorff [25] explained why governments prefer VERs to tariff in a Cournot model. Also, Ishikawa [26] studied the effect of VERs on profit, market share, consumer surplus and welfare in a Cournot model. Berry, et al. [27] evaluated VERs that was initially placed on automobiles exports from Japan in 1980's. They found that VERs had increased both prices and the profits of domestic firms, while leaving consumer welfare worse off. Feenstra and Lewis [28] considered a domestic government with political pressure to negotiate over the volume of trade and the transfer of rents. They characterized the globally optimal, incentive-compatible trade policies, in which the domestic government has no incentive to overstate (or understate) the pressure for protection. De Santis [14] studied the impact of VERs on exporting countries. He showed that VERs at the free-trade level would favour the concentration of industry, and raise the price mark-up in the domestic market. However, the impact on welfare is indeterminate depending upon the effect on global efficiency.

Second, $\bar{q}_{i}^{j}$ in (2) tells us something about the motivation of mimicking. Notice that $\bar{q}_{i}^{j}$ is decreasing in $c_{i}$, and this indicates that a more efficient firm will have a higher VER. In particular, if $c_{i}$ has two possible values: $c^{H}$ and $c^{L}$ with $c^{H}>c^{L}$, then we have $\bar{q}_{i}^{j}\left(c^{H}\right)<\bar{q}_{i}^{j}\left(c^{L}\right)$. This, however, does not imply that the less efficient firm will mimic the efficient firm. Actually, since $\pi_{i}$ is concave in $q_{i}^{j}$, and by the definition of maximization, the less efficient firm $\left(c^{H}\right)$ is better off choosing $\bar{q}_{i}^{j}\left(c^{H}\right)$ than choosing $\bar{q}_{i}^{J}\left(c^{L}\right)$. In the words of Spence [29], the inefficient firm does not envy the efficient firm. This means that when we consider incomplete information in a unilateral intervention case, a separating equilibrium where each type of $c_{i}$ chooses its intended VER $\bar{q}_{i}^{j}\left(c_{i}\right)$ might exist. Hence, our model would suggest the same result as Qiu [2] in the unilateral intervention case. In the next section, we will show that with multiple mechanisms, a separating equilibrium does not exist.

\section{Incomplete Information VERs Game}

Section 3 discusses the incomplete information VERs game where $c_{i}$ is only privately known by firm $i$. Neither government $i$ nor government $j$ or firm $j$ knows this value. To simplify the analysis, we assume a binary type set, $c_{i} \in\left\{c^{L}, c^{H}\right\}$ with $c^{H}>c^{L}$.

We have shown that with complete information, each government's VER decision is as efficient as in the single government case. There is no direct interaction between the two governments, so the policy efficiency can be retained even with bilateral interventions. With incomplete information, we will show that the "signaling effect" of menu selection will change the rival firm's perception about domestic firm's private information. Consequently, each firm's intention of information revelation will be related to the rival firm's intention, and the two governments are no longer "independent" from each other.

The incomplete information VERs game proceeds as follows. First, each government $i$ announces a VERs menu $\left\{q_{i}^{j}\left(c^{L}\right), q_{i}^{j}\left(c^{H}\right)\right\}$ independently. Second, each firm $i$ self selects a VER from the menu, and this choice is publicly observed. Third, according to the observed policy choices, the two firms update their beliefs about the rival firm's production cost, and then compete in the product markets of the two countries. By backward induction, we first solve the market equilibrium given the two firms' menu selection. Then we characterize the two firms' menu selection equilibrium. Finally, we determine each government's VERs menu.

Before proceeding with the derivation of market equilibrium, we define more notations for the prior and posterior beliefs on $c_{i}$. First, as said, we assume that $c_{i} \in\left\{c^{L}, c^{H}\right\}$ is only privately known by firm $i$. All other players (including government $i$, government $j$, and firm $j$ ) have common prior beliefs that the prob- 
ability for $c^{L}$ is $\mu, 0<\mu<1$ and the probability for $c^{H}$ is $1-\mu$. After observing the rival firm's menu selection strategy, each firm $i$ can update its belief on $c_{j}, i \neq j$.

Let $\sigma_{i} \equiv\left\{\sigma_{i}^{L}, \sigma_{i}^{H}\right\}$ denote firm $i$ 's selection strategy from the menu $\left\{q_{i}^{j}\left(c^{L}\right), q_{i}^{j}\left(c^{H}\right)\right\}$. It is assumed that $\sigma_{i}^{L}, \sigma_{i}^{H} \in \Delta\left\{q_{i}^{j}\left(c^{L}\right), q_{i}^{j}\left(c^{H}\right)\right\}$ for $i \neq j$. That is, in $\sigma_{i}$, the selection strategy for type $c^{L}$ of firm $i$ is $\sigma_{i}^{L} q_{i}^{j}\left(c^{L}\right)+\left(1-\sigma_{i}^{L}\right) q_{i}^{j}\left(c^{H}\right)$, and for type $c^{H}$ of firm $i$, it is $\sigma_{i}^{H} q_{i}^{j}\left(c^{L}\right)+\left(1-\sigma_{i}^{H}\right) q_{i}^{j}\left(c^{H}\right)$. In particular, $\left(\sigma_{i}^{L}=1, \sigma_{i}^{H}=0\right)$ denotes the separating strategy where each type of firm $i$ selects its intended VER. As another example, $\left(\sigma_{i}^{L}=1, \sigma_{i}^{H}=\lambda_{i}\right)$ denotes the hybrid strategy where type $c^{L}$ of firm $i$ selects its intended VER, while type $c^{H}$ of firm $i$ randomly selects between $q_{i}^{j}\left(c^{L}\right)$ and $q_{i}^{j}\left(c^{H}\right)$ with a probability $\lambda_{i}$.

\subsection{Market Equilibrium}

Belief Updating We now solve the market equilibrium given the two firms' menu selection. After observing firm $i$ 's selection strategy, firm $j$ can update its belief on $c_{i}$. That is, according to the Bayes' rule, given the observation $\sigma_{i}$, the on-equilibrium path belief is given by:

$$
\mu_{\sigma_{i}}=\frac{\sigma_{i}^{L} \mu}{\sigma_{i}^{L} \mu+\sigma_{i}^{H}(1-\mu)}
$$

For simplification, we assume that the off-equilibrium path belief will be the same as the prior $\mu$.

If $\sigma_{i}^{L}>\sigma_{i}^{H}$ then it can be calculated that $\mu_{\sigma_{i}}>\mu$. In particular, for the separating strategy

$\left(\sigma_{i}^{L}=1, \sigma_{i}^{H}=0\right)$, we have $\mu_{\sigma_{i}}=1$. As another example, for the hybrid strategy $\left(\sigma_{i}^{L}=1, \sigma_{i}^{H}=\lambda_{i}\right)$, we have

$\mu_{\sigma_{i}}=\frac{\sigma_{i}^{L} \mu}{\sigma_{i}^{L} \mu+\sigma_{i}^{H}(1-\mu)}$ and $\mu<\mu_{\sigma_{i}}<1$. Finally,

given the posterior belief $\mu_{\sigma_{i}}$, let

$E_{\sigma_{i}} c_{i}=\mu_{\sigma_{i}} c^{L}+\left(1-\mu_{\sigma_{i}}\right) c^{H}$ denote firm $i$ 's posterior expected cost.

Market Competition Let $q_{i}^{j}\left(\sigma_{i}\right)$ denote country $i$ 's VER associated with selection strategy $\sigma_{i}$. Since each firm's profit will be affected by their selection strategies, we rewrite the profits as $\pi_{i}\left(\sigma_{1}, \sigma_{2}, c_{i}\right), i=1,2$, where

$$
\begin{aligned}
\pi_{1}\left(\sigma_{1}, \sigma_{2}, c_{1}\right)= & \left\{\alpha-\beta q_{1}^{1}-\gamma E q_{2}^{1}\left(\sigma_{2}\right)\right\} q_{1}^{1} \\
& +\left\{\alpha-\beta q_{2}^{2}-\gamma q_{1}^{2}\left(\sigma_{1}\right)\right\} q_{1}^{2}\left(\sigma_{1}\right) \\
& -c_{1}\left\{q_{1}^{1}+q_{1}^{2}\left(\sigma_{1}\right)\right\},
\end{aligned}
$$

$$
\begin{aligned}
\pi_{2}\left(\sigma_{1}, \sigma_{2}, c_{2}\right)= & \left\{\alpha-\beta q_{1}^{1}-\gamma q_{2}^{1}\left(\sigma_{2}\right)\right\} q_{2}^{1}\left(\sigma_{2}\right) \\
& +\left\{\alpha-\beta q_{2}^{2}-\gamma E q_{1}^{2}\left(\sigma_{1}\right)\right\} q_{2}^{2} \\
& -c_{2}\left\{q_{2}^{1}\left(\sigma_{2}\right)+q_{2}^{2}\right\} .
\end{aligned}
$$

In the case of $\pi_{1}\left(\sigma_{1}, \sigma_{2}, c_{i}\right)$, there is an expected term $E q_{2}^{1}\left(\sigma_{2}\right)$. The reason for the expectation form is because firm 1 cannot observe $c_{2}$, and by observing $\sigma_{2}$, firm 1 will guess firm 2'sVER as:

$$
\begin{aligned}
E q_{2}^{1}\left(\sigma_{2}\right)= & {\left[\mu \sigma_{2}^{L}+(1-\mu) \sigma_{2}^{H}\right] q_{2}^{1}\left(c^{L}\right) } \\
& +\left[\mu\left(1-\sigma_{2}^{L}\right)+(1-\mu)\left(1-\sigma_{2}^{H}\right)\right] q_{2}^{1}\left(c^{H}\right) .
\end{aligned}
$$

Given $\sigma_{2}=\left(\sigma_{2}^{L}, \sigma_{2}^{H}\right)$, the probability that type $c^{L}$ of firm 2 takes $q_{2}^{1}\left(c^{L}\right)$ is $\sigma_{2}^{L}$, and the probability that type $c^{H}$ of firm 2 takes $q_{2}^{1}\left(c^{L}\right)$ is $\sigma_{2}^{H}$. So the expected probability of taking $q_{2}^{1}\left(c^{L}\right)$ is $\mu \sigma_{2}^{L}+(1-\mu) \sigma_{2}^{H}$. The expected probability of taking $q_{2}^{1}\left(c^{H}\right)$ can be explained similarly.

In the product market, each firm chooses $q_{i}^{i}$ to maximize $\pi_{i}\left(\sigma_{1}, \sigma_{2}, c_{i}\right)$, given the selection strategy $\left(\sigma_{1}, \sigma_{2}\right)$. Notice that $q_{i}^{j}\left(\sigma_{i}\right), i \neq j$, will be determined by the menu selection strategy. By the first order condition of maximization ${ }^{4}$, we have

$$
q_{1}^{1}=\frac{\alpha-\gamma E q_{2}^{1}\left(\sigma_{2}\right)-c_{1}}{2 \beta} \text { and } q_{2}^{2}=\frac{\alpha-\gamma E q_{1}^{2}\left(\sigma_{1}\right)-c_{2}}{2 \beta} .
$$

This is similar to (1) in the complete information case, except that the expected VERs will be determined in the menu selection game.

Substitute the two best replies in (6) to (4) and (5), we can rewrite $\pi_{i}\left(\sigma_{1}, \sigma_{2}, c_{i}\right)$ as:

$$
\begin{aligned}
\pi_{1}\left(\sigma_{1}, \sigma_{2}, c_{1}\right)= & \frac{\left[\alpha-\gamma E q_{2}^{1}\left(\sigma_{2}\right)\right]^{2}-\left(c_{1}\right)^{2}}{2} \\
& +\frac{\alpha-\gamma q_{1}^{2}\left(\sigma_{1}\right)+E_{\sigma_{2}} c_{2}}{2} q_{1}^{2}\left(\sigma_{1}\right) \\
& -c_{1}\left\{\frac{\alpha-\gamma E q_{2}^{1}\left(\sigma_{2}\right)-c_{1}}{2 \beta}+q_{1}^{2}\left(\sigma_{1}\right)\right\}, \\
\pi_{2}\left(\sigma_{1}, \sigma_{2}, c_{2}\right)= & \frac{\left[\alpha-\gamma E q_{1}^{2}\left(\sigma_{1}\right)\right]^{2}-\left(c_{2}\right)^{2}}{2} \\
& +\frac{\alpha-\gamma q_{2}^{1}\left(\sigma_{2}\right)+E_{\sigma_{1}} c_{1}}{2} q_{2}^{1}\left(\sigma_{2}\right) \\
& -c_{2}\left\{\frac{\alpha-\gamma E q_{1}^{2}\left(\sigma_{1}\right)-c_{2}}{2 \beta}+q_{2}^{1}\left(\sigma_{2}\right)\right\} .
\end{aligned}
$$

${ }^{4}$ The second order condition of maximization is satisfied. 
In the case of $\pi_{1}\left(\sigma_{1}, \sigma_{2}, c_{1}\right)$, notice that there is a posterior expected cost term $E_{\sigma_{2}} c_{2}$. From (6), we know that firm 2's best reply is $\frac{\alpha-\gamma E q_{1}^{2}\left(\sigma_{1}\right)-c_{2}}{2 \beta}$. But since firm 1 cannot observe $c_{2}$, it can only use the observation of $\sigma_{2}$ to update its belief to be

$E_{\sigma_{2}} c_{2}=\mu_{\sigma_{2}} c^{L}+\left(1-\mu_{\sigma_{2}}\right) c^{H}$. The similar argument applies to firm 2 .

\subsection{Menu Selection}

First, recall that in the complete information case, we conclude that type $c^{H}$ is better off choosing $\bar{q}_{i}^{j}\left(c^{H}\right)$ than $\bar{q}_{i}^{j}\left(c^{L}\right)$. In the unilateral intervention case, a separating equilibrium where each type of $c_{i}$ chooses its intended VER $\bar{q}_{i}^{j}\left(c^{H}\right)$ might exist. Hence, to simplify the discussion, we restrict the selection strategy $\sigma_{i} \equiv\left(\sigma_{i}^{L}, \sigma_{i}^{H}\right)$ to be $\sigma_{i} \equiv\left(1, \lambda_{i}\right)$. That is, we assume that type $c^{L}$ will take the intended VER, while type $c^{H}$ might mimic type $c^{L}$ by taking a mixed strategy $\lambda_{i} q_{i}^{j}\left(c^{L}\right)+\left(1-\lambda_{i}\right) q_{i}^{j}\left(c^{H}\right)$. With this restriction, $\lambda_{i}=0$ will indicate the separating strategy where each type chooses its intended VER, and $\lambda_{i}=1$ denotes the pooling strategy where both types $c^{L}$ and $c^{H}$ choose $q_{i}^{j}\left(c^{L}\right)$.

(7) and (8) can be rewritten accordingly. $E_{\sigma_{1}} c_{i}$ can be written as

$$
\begin{aligned}
E_{\sigma_{1}} c_{i} & =\mu_{\sigma_{i}} c^{L}+\left(1-\mu_{\sigma_{i}}\right) c^{H}, \\
& =c^{H}-\frac{1 \mu}{1 \mu+\lambda_{i}(1-\mu)}\left(c^{H}-c^{L}\right) .
\end{aligned}
$$

and $E_{\sigma_{1}} q_{i}^{j}\left(\sigma_{i}\right)$ can be rewritten as

$$
\begin{aligned}
E_{\sigma_{1}} q_{i}^{j}\left(\sigma_{i}\right)= & {\left[\mu+(1-\mu) \lambda_{i}\right] q_{i}^{j}\left(c^{L}\right) } \\
& +\left[(1-\mu)\left(1-\lambda_{i}\right)\right] q_{i}^{j}\left(c^{H}\right)
\end{aligned}
$$

Lemma 1 concludes a preliminary result which will be useful for equilibrium characterization.

Lemma $1 \frac{\partial E_{\sigma_{1}} c_{i}}{\partial \lambda_{i}}>0$

Proof. Since $\frac{\partial E_{\sigma_{1}} c_{i}}{\partial \mu \lambda_{i}}=-\left(c^{H}-c^{L}\right)<0$ and

$\frac{\partial \mu \lambda_{i}}{\partial \lambda_{i}}=\frac{-(1-\mu)}{\left(1 \mu+\lambda_{i}(1-\mu)\right)^{2}}<0$, we have

$\frac{\partial E_{\sigma_{1}} c_{i}}{\partial \lambda_{i}}=\left(c^{H}-c^{L}\right) \frac{(1-\mu)}{\left(1 \mu+\lambda_{i}(1-\mu)\right)^{2}}>0$.

Next, we derive the equilibrium selection strategies $\left(\sigma_{1}, \sigma_{2}\right)$, given the best replies in (6). That is, for $i=1,2$ and $c_{i}=c^{L}, c^{H}$, firm $i$ maximizes

$\pi_{i}\left(\sigma_{1}, \sigma_{2}, c_{i}\right)$ with respect to $\sigma_{i}$. In the case of firm 1 , after replacing $\sigma_{i}=\left(1, \lambda_{i}\right), \pi_{1}\left(\sigma_{1}, \sigma_{2}, c_{1}\right)$ in (7) is rewritten as (see Equation (11)):

In $\sigma_{1} \equiv\left(1, \lambda_{1}\right)$, type $c^{L}$ will take the intended VER, and type $c^{H}$ will mimic type $c^{L}$ by taking a mixed strategy $\lambda_{1} q_{1}^{2}\left(c^{L}\right)+\left(1-\lambda_{1}\right) q_{1}^{2}\left(c^{H}\right)$. So in (11), we have replaced $q_{1}^{2}\left(\sigma_{1}\right)$ in (7) by $q_{1}^{2}\left(c^{L}\right)$. Also in (12), we have replaced $q_{1}^{2}\left(\sigma_{1}\right)$ in (7) by

$\lambda_{1} q_{1}^{2}\left(c^{L}\right)+\left(1-\lambda_{1}\right) q_{1}^{2}\left(c^{H}\right)$. Also, we have replaced $E_{\sigma_{2}} c_{2}$ and $E q_{2}^{1}\left(\sigma_{2}\right)$ with the definitions given in (9) and (10). The similar argument applies to firm 2.

Selection Equilibrium Given the announced VERs menu $\left\{q_{i}^{j}\left(c^{L}\right), q_{i}^{j}\left(c^{H}\right)\right\},\left(\sigma_{1}, \sigma_{2}\right)$ will constitute a Bayesian equilibrium iff for $i=1,2$,

$$
\max _{\sigma_{i}} \pi_{i}\left(\sigma_{1}, \sigma_{2}, c_{i}\right) \text { for } c_{i}=c^{L}, c^{H} .
$$

We need to show that for $i=1,2, \sigma_{i}^{L}=1$ and $\sigma_{i}^{H}=\lambda_{i}$ can maximize $\pi_{i}\left(\sigma_{1}, \sigma_{2}, c_{i}\right)$ for $c_{i}=c^{L}, c^{H}$, respectively. First, from (11), if we require $\sigma_{1}^{L}=1$ to be best reply for type $c^{L}$, the intended VER must be set at the following level

$$
\begin{aligned}
& \pi_{1}\left(\sigma_{1}, \sigma_{2}, c^{L}\right)= \frac{\left[\alpha-\gamma E q_{2}^{1}\left(\sigma_{2}\right)\right]^{2}-\left(c^{L}\right)^{2}}{2}+\frac{\alpha-\gamma q_{1}^{2}\left(c^{L}\right)+E_{\sigma_{2}} c_{2}}{2} q_{1}^{2}\left(c^{L}\right) \\
&-c^{L}\left\{\frac{\alpha-\gamma E q_{2}^{1}\left(\sigma_{2}\right)-c^{L}}{2 \beta}+q_{1}^{2}\left(c^{L}\right)\right\}, \\
& \pi_{1}\left(\sigma_{1}, \sigma_{2}, c^{H}\right)= \frac{\left[\alpha-\gamma E q_{2}^{1}\left(\sigma_{2}\right)\right]^{2}-\left(c^{H}\right)^{2}}{2} \\
&+ \frac{\alpha-\gamma\left[\lambda_{1} q_{1}^{2}\left(c^{L}\right)+\left(1-\lambda_{1}\right) q_{1}^{2}\left(c^{H}\right)\right]+E_{\sigma_{2}} c_{2}}{2}\left[\lambda_{1} q_{1}^{2}\left(c^{L}\right)+\left(1-\lambda_{1}\right) q_{1}^{2}\left(c^{H}\right)\right] \\
&-c^{H}\left\{\frac{\alpha-\gamma E q_{2}^{1}\left(\sigma_{2}\right)-c^{H}}{2 \beta}+\left[\lambda_{1} q_{1}^{2}\left(c^{L}\right)+\left(1-\lambda_{1}\right) q_{1}^{2}\left(c^{H}\right)\right]\right\} .
\end{aligned}
$$




$$
\tilde{q}_{1}^{2}\left(c^{L}\right)=\frac{1}{2 \gamma}\left(\alpha-2 c^{L}+E_{\sigma_{2}} c_{2}\right),
$$

which is obtained by differentiating (11) with respect to $q_{1}^{2}\left(c^{L}\right)$. In other words, if $q_{1}^{2}\left(c^{L}\right)$ is set to be (13), then
$\sigma_{1}^{L}=1$ will be best reply.

Next, for type $c^{H}, \sigma_{1}^{H}=\lambda_{1}$ needs to be best reply to $\sigma_{2}=\left(1, \lambda_{2}\right)$. That is, given $\sigma_{2}$, the first order condition of maximization for (12) is:

$$
\begin{aligned}
& \frac{\partial \pi_{1}\left(\sigma_{1}, \sigma_{2}, c^{H}\right)}{\partial \lambda_{1}}=\frac{-\gamma}{2}\left[q_{1}^{2}\left(c^{L}\right)-q_{1}^{2}\left(c^{H}\right)\right]\left\{q_{1}^{2}\left(c^{H}\right)+\lambda_{1}\left[q_{1}^{2}\left(c^{L}\right)-q_{1}^{2}\left(c^{H}\right)\right]\right\} \\
& +\frac{\alpha-\gamma\left\{q_{1}^{2}\left(c^{H}\right)+\lambda_{1}\left[q_{1}^{2}\left(c^{L}\right)-q_{1}^{2}\left(c^{H}\right)\right]\right\}+E_{\sigma_{2}} c_{2}}{2}\left[q_{1}^{2}\left(c^{L}\right)-q_{1}^{2}\left(c^{H}\right)\right] \\
& -c^{H}\left\{q_{1}^{2}\left(c^{L}\right)-q_{1}^{2}\left(c^{H}\right)\right\} .
\end{aligned}
$$

Let $B_{1}=\left[q_{1}^{2}\left(c^{L}\right)-q_{1}^{2}\left(c^{H}\right)\right]$, firm 1's best reply is:

$$
\lambda_{1}=\frac{\alpha-2 \gamma\left\{q_{1}^{2}\left(c^{H}\right)\right\}-2 c^{H}+E_{\sigma_{2}} c_{2}}{2 B_{1} \gamma} .
$$

Similarly, we can calculate firm 2's best reply to $\sigma_{1}=\left(1, \lambda_{1}\right)$ :

$$
\lambda_{2}=\frac{\alpha-2 \gamma\left\{q_{2}^{1}\left(c^{H}\right)\right\}-2 c^{H}+E_{\sigma_{1}} c_{1}}{2 B_{2} \gamma},
$$

where $B_{2}=\left[q_{2}^{1}\left(c^{L}\right)-q_{2}^{1}\left(c^{H}\right)\right]$. Notice that $\lambda_{i}$ is related to $\lambda_{j}$ through the term $E_{\sigma_{j}} c_{j}$.

The equilibrium $\left(\lambda_{1}, \lambda_{2}\right)$ needs to simultaneously satisfy (14) and (15). However, since the structure forms of equilibrium $\left(\lambda_{1}, \lambda_{2}\right)$ are complicated, we derive the following properties on the menu selection equilibrium.

First, from (14), it can be calculated that

$$
\begin{aligned}
& \frac{\partial \lambda_{1}}{\partial \lambda_{2}}=\frac{1}{2 B_{1} \gamma} \frac{\partial E_{\sigma_{2}} c_{2}}{\partial \lambda_{2}} \\
& =\frac{1}{2 B_{1} \gamma}\left(c^{H}-c^{L}\right) \frac{(1-\mu)}{\left(1 \mu+\lambda_{2}(1-\mu)\right)^{2}}>0 .
\end{aligned}
$$

A similar argument on $\lambda_{2}$ also shows that $\frac{\partial \lambda_{2}}{\partial \lambda_{1}}>0$. This indicates that $\lambda_{1}$ and $\lambda_{2}$ are strategic complements. Since the level of $\lambda_{i}$ denotes the degree that type $c^{H}$ of firm $i$ will mimic type $c^{L}$ the more that type $c^{H}$ of firm $i$ lies will trigger $c^{H}$ type of the rival firm to lie more. Next, recall that the level of $\gamma$ measures the degree of substitution, and the smaller $\gamma$ indicates a higher degree of product differentiation. If we take the partial differentiation of $\frac{\partial \lambda_{1}}{\partial \lambda_{2}}$ with respect to $\gamma$, we know that the degree of strategic complements is positively related to the degree of product differentiation.

Lemma $2 \lambda_{1}$ and $\lambda_{2}$ are strategic complements, and $\frac{\partial \lambda_{1}}{\partial \lambda_{2}}$ is decreasing in $\gamma$.

Second, it is interesting to know if the separating equilibrium exists. That is, in the case of firm 1, we ask if $\lambda_{1}=0$ is a best reply to $\lambda_{2}=0$ in (14). To find out, substitute $\lambda_{2}=0$ in (14), so we have $E_{\sigma_{2}} c_{2}=c^{L}$ and firm 1 's best reply in (14) becomes

$\lambda_{1}=\frac{\alpha-2 \gamma\left\{q_{1}^{2}\left(c^{H}\right)\right\}-2 c^{H}+c^{L}}{2 B \gamma}$. The only chance for $\lambda_{1}=0$ is to let

$$
q_{1}^{2}\left(c^{H}\right)=\frac{1}{2 \gamma}\left(\alpha-2 c^{H}+c^{L}\right)
$$

Compare this level to the efficient VER $\bar{q}_{1}^{2}\left(c^{H}\right)=\frac{1}{2 \gamma}\left(\alpha-2 c_{1}+c_{2}\right)$. We can conclude that if $c_{2}=c^{L}$, these two values are identical, but if $c_{2}=c^{H}$, $\bar{q}_{1}^{2}$ is higher. In other words, the efficient VERs can indeed induce a truth-telling equilibrium but only when $c_{2}=c^{L}$.

More interestingly, if we consider an arbitrary positive level of $\lambda_{2}$, the VER for (14) to be zero is:

$$
\tilde{q}_{1}^{2}\left(c^{H}\right)=\frac{\alpha-2 c^{H}+E_{\sigma_{2}} c_{2}}{2 \gamma}
$$

Also recall $\tilde{q}_{1}^{2}\left(c^{L}\right)$ from (13). We therefore have the menu $\left\{\tilde{q}_{1}^{2}\left(c^{L}\right), \tilde{q}_{1}^{2}\left(c^{H}\right)\right\}$, which will induce each type of firm 1 to tell the truth, no matter what the rival will do. In other words, given the menu $\left\{\tilde{q}_{1}^{2}\left(c^{L}\right), \tilde{q}_{1}^{2}\left(c^{H}\right)\right\}$, the dominant strategy for each type of firm 1 is to tell the truth and pick the intended VER.

Lemma 3 1) Given the menu $\left\{\tilde{q}_{1}^{2}\left(c^{L}\right), \tilde{q}_{1}^{2}\left(c^{H}\right)\right\}$, the dominant strategy for each type of firm 1 is to tell the truth and pick the intended VER. 2) The efficient VERs can indeed induce a truth-telling equilibrium but only when $c_{2}=c^{L}$.

In the incomplete information VERs game, the "sig- 
naling effect" of menu selection will change the rival firm's perception about domestic firm's private information. Consequently, each firm's intention of information revelation will be related to the rival firm's intention. The question of concern is whether the government will find it optimal to induce truthtelling, no matter how the rival firms might lie. Will it be better off for the government to induce a certain degree of lying in equilibrium? How will this degree relate to the market structure? We will provide answers to these questions shortly in next subsection.

Finally, it can be calculated from (14) for the following preliminary results.

$$
\text { Lemma } 4 \frac{\partial \lambda_{1}}{\partial q_{1}^{2}\left(c^{H}\right)}<0 \text { and } \frac{\partial \lambda_{1}}{\partial \gamma}<0 \text {. }
$$

As illustrated in Figure 1, increasing $q_{1}^{2}\left(c^{H}\right)$ will shift the best reply of $\lambda_{1}$ inward. When $q_{1}^{2}\left(c^{H^{H}}\right)$ increases, the menu selection equilibrium will move from $E_{0}$ to $E_{1}$. Since $\lambda_{1}$ and $\lambda_{2}$ are strategic complements, this indicates that both $\lambda_{1}$ and $\lambda_{2}$ will decrease.

Next, $\frac{\partial \lambda_{1}}{\partial \gamma}<0$ indicates that the smaller $\gamma$ is, the more the best reply of $\lambda_{1}$ will shift outward. In other words, when the two products become more differentiated, the more likely that type $c^{H}$ will lie. Intuitively, when the two products are more differentiated, each firm will hope to increase their actual export to counteract the demand reduction from a smaller $\gamma$. Since we are restricting $q_{1}^{2}\left(c^{L}\right)>q_{1}^{2}\left(c^{H}\right)$, type $c^{H}$ of each firm has more intention to lie and hence $\lambda_{1}$ becomes higher.

\subsection{Equilibrium VERs}

Given the market equilibrium in (6) and the menu selection equilibrium determined by (14) and (15), we now

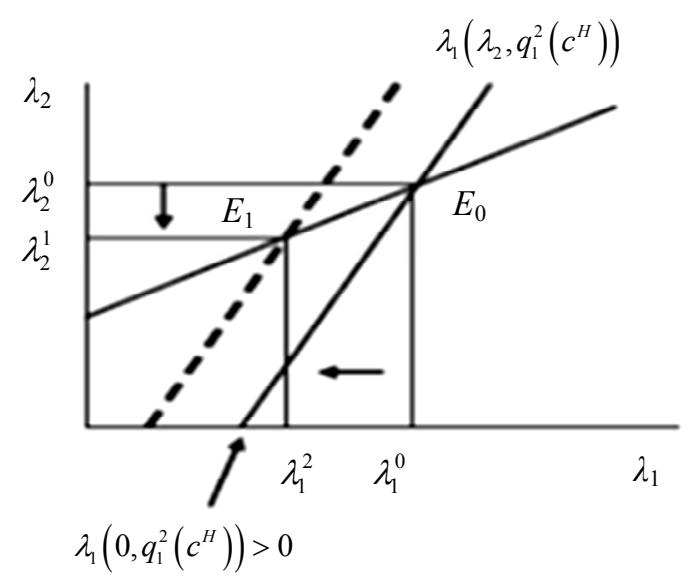

Figure 1. Increasing $q_{1}^{2}\left(c^{H}\right)$ shifts the best replies leftward. determine each government's menu of VERs. As said, we have simplified the discussion by restrict the selection strategy $\sigma_{i} \equiv\left(\sigma_{i}^{L}, \sigma_{i}^{H}\right)$ to be $\sigma_{i} \equiv\left(1, \lambda_{i}\right)$. In the case of firm 1 , according to the discussion on menu selection, if we require $\sigma_{1}^{L}=1$ to be best reply for type $c^{L}$, the intended VER must be set at the following level

$$
\tilde{q}_{1}^{2}\left(c^{L}\right)=\frac{\alpha-2 c^{L}+E_{\sigma_{2}} c_{2}}{2 \gamma}
$$

The same argument can apply to firm2. Hence we are left with the determination on $q_{i}^{j}\left(c^{L}\right)$. As mentioned in Lemma 3 that the menu $\left\{\tilde{q}_{1}^{2}\left(c^{L}\right), \tilde{q}_{1}^{2}\left(c^{H}\right)\right\}$ (from (13) and (16)) can induce $\lambda_{1}=0$ for any level of $\lambda_{2}$. The question of concern is whether the government will find it optimal to induce truth-telling from its own firm, no matter how the rival firms might lie.

To answer the question, we first calculate the first or der condition of maximization: $\frac{\partial E W_{i}}{\partial q_{i}^{j}\left(c^{H}\right)}=0$. In the case of firm 1, recall $S W_{1}\left(c_{1}\right)$ from Section 2:

$$
\begin{aligned}
S W_{1}\left(c_{1}\right)= & U_{1}\left(c_{1}\right)-R_{j}^{i}\left(c_{1}\right)+R_{i}^{j}\left(c_{1}\right)-c_{i}\left(q_{i}^{i}+q_{i}^{j}\right) \\
= & \alpha\left(q_{1}^{1}+q_{2}^{1}\right)-\left[\beta\left(q_{1}^{1}\right)^{2}+2 \gamma q_{1}^{1} q_{2}^{1}+\beta\left(q_{2}^{1}\right)^{2}\right] / 2 \\
& -R_{2}^{1}\left(c_{1}\right)+R_{1}^{2}\left(c_{1}\right)-c_{1}\left(q_{1}^{1}+q_{1}^{2}\right) .
\end{aligned}
$$

The expected social welfare is: $E W_{1}=\mu S W_{1}\left(c^{L}\right)+(1-\mu) S W_{1}\left(c^{H}\right)$. Since the structural forms are complicated, we omitted for the detailed derivation of $\frac{\partial E W_{i}}{\partial q_{i}^{j}\left(c^{H}\right)}{ }^{5}$. Then, by applying the implicit function theorem, we can calculate $\frac{\partial q_{i}^{j}\left(c^{H}\right)}{\partial q_{j}^{i}\left(c^{H}\right)}$, the sign of which can tell us wether the two policies are strategic complements or substitutes. Finally, we check whether it is dominant for government 1 to choose

$\left\{\tilde{q}_{1}^{2}\left(c^{L}\right), \tilde{q}_{1}^{2}\left(c^{H}\right)\right\}$, such that $\lambda_{1}=0$. The same argument can apply to firm 2 .

Proposition $5 q_{1}^{2}\left(c^{H}\right)$ and $q_{2}^{1}\left(c^{H}\right)$ are strategic complements for $\mu \leq \mu^{*}$, and they are strategic substitutes for $\mu>\mu^{*}$.

Recall from Lemma 2 and 4 that $\lambda_{1}$ and $\lambda_{2}$ are strategic complements and $\frac{\partial \lambda_{i}}{\partial q_{i}^{j}\left(c^{H}\right)}<0$. Proposition 5 says that the key to judge the strategic relation between $q_{1}^{2}\left(c^{H}\right)$ and $q_{2}^{1}\left(c^{H}\right)$ is the size of prior belief $\mu$. In the case of government 1 , if she thinks that the domestic firm is more likely to be efficient (i.e., $\mu>\mu^{*}$ ), then when government 2 increases $q_{2}^{1}\left(c^{H}\right)$, the best reply of

${ }^{5}$ Detailed derivations are available upon request. 
$\lambda_{2}$ will shift inward. Since $\lambda_{1}$ and $\lambda_{2}$ are strategic complements, the equilibrium $\left(\lambda_{1}, \lambda_{2}\right)$ will both decrease. Now, if $q_{1}^{2}\left(c^{H}\right)$ decreases, then the best reply of $\lambda_{2}$ will shift outward, which could cause the equilibrium $\lambda_{1}$ to increase rather than decrease.

Contrarily, if government 1 thinks the domestic firm is more likely to have $c^{H}$ (i.e., $\mu \leq \mu^{*}$ ), then it is better to allure the type $c^{H}$ of the rival firm to lie less. To do so, when government 2 increases $q_{2}^{1}\left(c^{H}\right)$ and move the best reply of $\lambda_{2}$ inward, government 1 must also increase $q_{1}^{2}\left(c^{H}\right)$ and move the best reply of $\lambda_{1}$ inward to decrease both of $\lambda_{1}$ and $\lambda_{2}$ in equilibrium.

Martina and Vergoted [15] discussed the role of retaliation in trade agreements. They showed that in the presence of private information, retaliation can always be used to increase the welfare derived from such agreements by the participating governments. In particular, it is shown that retaliation is a necessary feature of any efficient equilibrium. Our results show that retaliation can only happen when $\mu \leq \mu^{*}$.

Proposition 6 Given any level of $\lambda_{j}$, it is optimal for the government to implement $\lambda_{i}>0$.

In the case of firm 1, to see whether it is optimal for government 1 to choose $\left\{\tilde{q}_{1}^{2}\left(c^{L}\right), \tilde{q}_{1}^{2}\left(c^{H}\right)\right\}$ (from (13) and (15)) to implement $\lambda_{1}=0$, we substitute $\tilde{q}_{1}^{2}\left(c^{L}\right)$ and $\tilde{q}_{1}^{2}\left(c^{H}\right)$ into the first order condition $\frac{\partial E W_{i}}{\partial q_{i}^{j}\left(c^{H}\right)}$. In the Appendix, we show that $\frac{\partial E W_{i}}{\partial q_{i}^{j}\left(c^{H}\right)}<0$ under the VERs menu $\left\{\tilde{q}_{1}^{2}\left(c^{L}\right), \tilde{q}_{1}^{2}\left(c^{H}\right)\right\}^{6}$. Due to the concavity of $E W_{i}$, we can conclude that the optimal $q_{1}^{2}\left(c^{H}\right)$ must be smaller than $\tilde{q}_{1}^{2}\left(c^{H}\right)$. By Lemma 2, since $\frac{\partial \lambda_{1}}{\partial q_{1}^{2}\left(c^{H}\right)}<0$, we can conclude that givenany level of $\lambda_{2}$, it is optimal for government 1 to implement $\lambda_{1}$.

\section{Concluding Remarksss}

We study the informational impacts of multilateral voluntary export restraints in a heterogenous version of Brander and Krugman's [30] international trade model. Similar to the unilateral intervention case such as Qiu [2] and Collie and Hviid [6], we ask if separating equilibrium where each country's domestic firm truthfully reveals its private information still exists. If not, how much information can be revealed? How does information revelation relate to market structure? Will there be trade retaliation?

${ }^{6}$ Detailed derivations are available upon request.
To these questions, we first showed that with competing mechanisms, the two firms' lying intentions are strategic complements and will increase with the degree of product differentiation. Next, we showed that each government will design their VERs menus to allow for only partial revelation. Contrary to the single intervention case [2], a separating equilibrium where each country's domestic firm truthfully reveals its private information does not exist with multilateral interventions. Finally, we demonstrated that trade retaliation, when the two governments' VERs are positively related, will happen when the government believes that its domestic firm is more likely to be inefficient.

As mentioned, we have restricted our discussion on the VERs game to an intra-industry trade model, for both analytical convenience and for complementation to the literature. It is also interesting to extend our model to discuss other policy instruments such as subsidies or taxes, and in another form of competition such as Cournot and Bertrand models. The literature has shown that the type of export policy is sensitive to the form of competition. In the case of subsidies or taxes, the informational impacts will not be as surprising as in VERs game, as the two governments are already related to each other with complete information. We will leave these interesting issues for further research.

\section{REFERENCES}

[1] H. H. Wang, C. Peng and H. Wu, "Tariffication and Welfare in a Differentiated Duopoly," The World Economy, Vol. 36, No. 7, 2013, pp. 899-911. http://dx.doi.org/10.1016/0022-1996(94)90007-8

[2] L. D. Qiu, "Optimal Strategic Trade Policy under Asymmetric Information," Journal of International Economics, Vol. 36, No. 3-4, 1994, pp. 333-354.

[3] J. A. Brander and B. J. Spencer, "Export Subsidies and International Market Share Rivalry," Journal of International Economics, Vol. 18, No. 1-2, 1985, pp. 83-100. http://dx.doi.org/10.1016/0022-1996(85)90006-6

[4] J. Eaton, and G. Grossman, "Optimal Trade and Industrial Policy under Oligopoly," Quarterly Journal of Economics, Vol. 101, No. 2, 1986, pp. 383-406. http://dx.doi.org/10.2307/1891121

[5] K. Wong, "Incentive Incompatible, Immiserizing Export Subsidies," University of Washington Discussion Paper No. 9020,1990 .

[6] D. R. Collie and M. Hviid, "Export Subsidies as Signals of Competitiveness," Scandinavian Journal of Economics, Vol. 95, No. 3, 1993, pp. 327-339. http://dx.doi.org/10.2307/3440359

[7] D. De Meza, "Export Subsidies and High Productivity: Cause or Effect," Canadian Journal of Economics, Vol. 19, No. 2, 1986, pp. 347-350. http://dx.doi.org/10.2307/135289

[8] J. P. Neary, "Cost Asymmetries in International Subsidy 
Games: Should Governments Help Winners or Losers?" Journal of International Economics, Vol. 37, No. 3-4, 1994, pp. 197-218. http://dx.doi.org/10.1016/0022-1996(94)90045-0

[9] S. Bandyopadhyay, "Demand Elasticities, Asymmetry and Strategic Trade Policy," Journal of International Economics, Vol. 42, No. 1-2, 1997, pp. 167-177. http://dx.doi.org/10.1016/S0022-1996(96)01453-5

[10] A. Dixit, "A Model of Duopoly Suggesting a Theory of Entry Barriers," Bell Journal of Economics, Vol. 10, No. 1, 1979, pp. 20-32. http://dx.doi.org/10.2307/3003317

[11] N. Singh and X. Vives, "Price and Quantity Competition in a Differentiated Duopoly," The RAND Journal of Economics, Vol. 15, No. 4, 1984, pp. 546-554. http://dx.doi.org/10.2307/2555525

[12] R. Harris, "Why Voluntary Export Restraints Are 'Voluntary'," The Canadian Journal of Economics, Vol. 18, No. 4, 1985, pp. 799-809. http://dx.doi.org/10.2307/135091

[13] C. C. Mai and H. H. Wang, "Why Voluntary Export Restraints Are Voluntary: An Extension," The Canadian Journal of Economics, Vol. 21, No. 4, 1988, pp. 877-882. http://dx.doi.org/10.2307/135273

[14] R. A. De Santis, "Why Exporting Countries Agree to Voluntary Export Restraints: The Oligopolistic Power of the Foreign Supplier," Scottish Journal of Political Economy, Vol. 50, No. 3, 2003, pp. 247-263. http://dx.doi.org/10.1111/1467-9485.5003009

[15] A. Martina and W. Vergoted, "On the Role of Retaliation in Trade Agreements," Journal of International Economics, Vol. 76, No. 1, 2008, pp. 61-77. http://dx.doi.org/10.1016/j.jinteco.2008.03.009

[16] J. Peck, "A Note on Competing Mechanisms and the Revelation Principle," Ohio State University, Mimeo, 1995.

[17] D. Martimort and L. Stole, "Communication Spaces, Equilibria Sets and the Revelation Principle under Common Agency," University of Chicago Graduate School of Business, Discussion Paper STE019, 1997.

[18] P. McAfee, "Mechanism Design by Competing Sellers," Econometrica, Vol. 61, No. 6, 1993, pp. 1281-1312. http://dx.doi.org/10.2307/2951643

[19] M. Peters, "On the Equivalence of Walrasian and NonWalrasian Equilibria in Contract Markets," Review of Economic Studies, Vol. 64, No. 2, 1997, pp. 241-265. http://dx.doi.org/10.2307/2971711

[20] M. Peters and S. Severinov, "Competition among Sellers Who Offer Auctions Instead of Prices," Journal of Economic Theory, Vol. 75, No. 1, 1997, pp. 141-179. http://dx.doi.org/10.1006/jeth.1997.2278

[21] S. L. Brainard and D. Martimort, "Strategic Trade Policy with Incomplete Informed Policymakers," Journal of International Economics, Vol. 42, No. 1-2, 1997, pp. 33-65. http://dx.doi.org/10.1016/S0022-1996(96)01446-8

[22] L. G. Epstein and M. Peters, "A Revelation Principle for Competing Mechanisms," Journal of Economic Theory, Vol. 88, No. 1, 1999, pp. 119-160. http://dx.doi.org/10.1006/jeth.1999.2542

[23] A. Creane and K. Miyagiwa, "Information and Disclosure in Strategic Trade Policy," Journal of International Economics, Vol. 75, No. 1, 2008, pp. 229-244. http://dx.doi.org/10.1016/i.jinteco.2007.11.002

[24] R. Myerson, "Optimal Coordination Mechanisms in Generalized Principal-Agent Problems," Journal of Mathematical Economics, Vol. 10, No. 1, 1982, pp. 67-81. http://dx.doi.org/10.1016/0304-4068(82)90006-4

[25] B. P. Rosendorff, "Voluntary Export Restraints, Antidumping Procedure, and Domestic Politics," American Economic Review, Vol. 86, No. 3, 1996, pp. 544-561.

[26] J. Ishikawa, "Who Benefits from Voluntary Export Restraints?" Review of International Economics, Vol. 6, No. 1, 1998, pp. 129-141. http://dx.doi.org/10.1111/1467-9396.00092

[27] S. Berry, J. Levinsohn and A. Pakes, "Voluntary Export Restraints on Automobiles: Evaluating a Trade Policy," American Economic Review, Vol. 89, No. 3, 1999, pp. 400-430. http://dx.doi.org/10.1257/aer.89.3.400

[28] R. C. Feenstra and T. R., Lewis, "Negotiated Trade Restrictions with Private Political Pressure," Quarterly Journal of Economics, Vol. 106, No. 4, 1991, pp. 1287-1307. http://dx.doi.org/10.2307/2937965

[29] M. Spence, “Job Market Signaling," Quarterly Journal of Economics, Vol. 87, No. 3, 1973, pp. 355-374. http://dx.doi.org/10.2307/1882010

[30] J. A. Brander and P. Krugman, "A Reciprocal Dumping Model of International Trade," Journal of International Economics, Vol. 15, No. 3-4, 1983, pp. 313-321. http://dx.doi.org/10.1016/S0022-1996(83)80008-7 